\title{
Prevalence of Low Back Pain among Higher Secondary School Teachers of Kanpur, India
}

\section{Gupta $\mathrm{G}^{* 1}$ and Sharma $\mathrm{A}^{2}$}

${ }^{1}$ Associate Professor, Krupanidhi College of Physiotherapy, Bangalore, Karnataka, India

${ }^{2}$ Saaii college of medical science and technology, kanpur, Uttar Pradesh, India

${ }^{*}$ Corresponding author: Gupta G, Krupanidhi College of Physiotherapy, 12/1, chikka Bellandur, Carmelaram post, Varthur hobli, off Sarjapur Road, Bangalore 560036, Karnataka, India, E-mail: gariace@gmail.com

Citation: Gupta G, Sharma A (2018) Prevalence of Low Back Pain among Higher Secondary School Teachers of Kanpur, India. J Orthop Physiother 1(1): 103. doi: 10.15744/2639-930X.1.103

Received Date: March 23, 2018 Accepted Date: September 18, 2018 Published Date: September 20, 2018

\begin{abstract}
Background: Low back pain is a global health issue, potentially affecting the individual's functionality in daily life. Teaching is regarded as a human service occupation and in recent years it is been identified as a highly stressful occupation.

Purpose: The purpose of present study was to evaluate the prevalence of low back pain (LBP) in higher secondary school teachers of Kanpur, India. An attempt was also made to establish a relationship between LBP, individual's ability to work and his/her psychological wellbeing, with specific reference to higher secondary school teachers of Kanpur, Uttar Pradesh, India.
\end{abstract}

Method: A sample of 321 higher secondary full time teachers, with a minimum of one year's experience, aged between 26 and 65 years, were selected. To answer the research question four appropriate scales were selected \{Nordic musculoskeletal questionnaire, Oswestry disability index, General Health Question - 12, and Work Ability Index\}.

Result: Analysis of data revealed that $27 \%$ of teachers reported acute episodes of LBP, and yearly prevalence was noted at $23.1 \%$. Around $58 \%$ of teachers were found to have minimal disability, $35.8 \%$ had moderate disability and $5 \%$ had severe disability primarily due to their LBP. Secondary findings of the study suggest that LBP had a significant impact on the working ability, and the psychological wellbeing of affected teachers.

Conclusion: The finding of present study suggests that even though acute as well as yearly prevalence of LBP among higher secondary school teachers was not very high but the disability caused by LBP affects routine performance of more than one-third of the teachers. LBP therefore has a negative impact on the work ability and general psychological well-being of many teachers.

Keywords: Low Back Pain; Work Ability; Psychological Wellbeing; Kanpur; India; Higher Secondary School Teachers

\section{Background}

Low back pain is a global public health issue and one of the most frequent musculoskeletal disorders experienced in our daily lives. It has a lifetime prevalence of $84 \%$. Extreme discomfort, costly medical treatments, and time lost from work are common sequel of low back pain $[1,2]$. LBP can be defined as the pain between the $12^{\text {th }}$ rib and the inferior gluteal folds (low back), with or without leg pain from various causes [2].

LBP can be classified as "specific" or "non-specific" LBP. Non-specific LBP is defined as having symptoms of unknown origin or without identifiable pathology whereas specific LBP is defined as one that is caused by a specific pathological and physiological mechanism, such as disc prolapse or herniated nucleus pulposus, infection, inflammatory arthopathy, tumor, osteoporosis or fracture [3]. LBP may not be a life threatening condition but it does constitute a major health problem in the world. It is usually accompanied by the painful limitation of movement, often influenced by physical activities and posture, and may be associated with referred pain [4]. Various individual factors are associated with low back pain, but a growing literature supports that occupational exposures is one of the major contributor to its occurrence and that this factor attributes $37 \%$ to LBP worldwide $[1]$. 
Some of the other risk factors associated with LBP are gender, age, lifestyle, and the psycho-social profile of a person's physical demands of the workplace, social support and pain perception. Recurrent weight lifting, using vibrating equipment, sedentary lifestyle, weakness of abdominal wall muscle, obesity, smoking, increase in lumber lordosis, scoliosis, cardiovascular disorders, low socio-economic status, and high body mass index (BMI) also contribute to LBP. Most of the mutable factors are occupationrelated: poor posturing, prolonged sitting, twisting, bending, stooping and lifting of heavy loads are some of the known risk factors for LBP [1,5-11]. It had been observed that individuals who suffered from LBP problem might develop major physical, social and mental disruptions, which could affect their occupations and their work ability. Physical impacts of low back pain may include the loss of physical function and deteriorated general health [5,12]. Recent studies have reported that psychological factors such as job dis-satisfaction or job-related strain also may be a risk factor of the LBP [7]. Work or job-related LBP denotes back pain originated in the context of work.

World Health Organization (WHO) has identified LBP as one of the top three occupational health problems to be targeted by surveillance within the WHO [9]. The mental impact of LBP includes anxiety, depression and sleeplessness, while poor physical performance and deterioration in general health status are the physical impact. LBP result in an inability to carry out social activities and it decreases the capability to perform occupational activities since it mostly affects adults of working age [10]. The direct and indirect costs of LBP in terms of quality of life, productivity, and employee absenteeism are enormous, thereby establishing this common condition as the single largest contributor to musculoskeletal disability word wide [11].

Work ability may be understood as 'how good is the worker at present, is expected to be in the near future, and how able is he/ she to do his/her work with respect to the work demands, health and mental resources'. This definition is based on a 'concept of work ability' (Ilmarinen, 2004) and according to it, work ability is the result of the interaction of the worker and his or her work. Work ability may also be described as the balance of the workers' resources and the work demands. On the basis of large clinical assessments and statistical analyses, the Work Ability Index, WAI is proved to be a good screening instrument for stress experience [12-14].

Teaching is regarded as a human service occupation. In recent time many studies have documented teaching as a highly stressful occupation [15]. There is a substantial body of literature describing it as stressful occupation and suggesting that teacher stress appears to be an increasing problem [16]. The work natures of school teachers involve a lot of head down posture, such as frequent reading, assignment correction, and writing on board. Activities of sustained sitting in front of computer, standing up teaching in class, repetitively overhead writing on board are also unsafe act found in teachers [17].

Stress is therefore held to be responsible for a vast and varied range of negative health outcomes that not only affect the individual, but also the employer and society in general.

Literature available on low back pain and the teaching occupation suggests that teachers are subjected to various stressful conditions during performing their duties. But the prevalence of LBP and their effect on the working ability and psychological wellbeing of higher secondary school teachers in Kanpur, India is not well documented. Thus in the present study an attempt has been made to study precisely this. Also, this study will attempt to establish the relationship between the low back pain, work ability and psychological wellbeing among higher secondary school teachers of Kanpur, India.

\section{Method}

This study was an epidemiological survey. It was approved by research committee of Saaii College of Medical Science and Technology, Kanpur University, India. A total sample of 321 full time higher secondary school teachers (class $6^{\text {th }}$ to class $12^{\text {th }}$ ) aged between 26 to 65 years with minimum of one year of experience were included $[9,19,20]$. Over a period of 1.5 month data was collected from 11 different higher secondary schools of Kanpur. Teachers who had any known chronic illness, neurological, musculoskeletal, cardiovascular or psychiatric illness with any prescribed medicines were excluded $[2,8,19]$. Also, teachers who reported resent history of fall, pregnancy, any known Disability by birth or who gave personal history of alcoholism, tobacco chewing and smoking were excluded from the study $[17,19,21]$. To answer the research question of prevalence of low back pain in school teachers four appropriately reliable and validated scales \{Nordic musculoskeletal questionnaire (NMQ), Oswestry disability index (ODI), General health questionnaire (GHQ), Work ability index (WAI) $\}$ were selected.

\section{Nordic Musculoskeletal Questionnaire}

The NMQ confirmed the pain in the nine areas of the body [neck, shoulder, elbows, wrist/hands upper back, lower back, thighs, knees and ankles], the response given by the patient was "yes" or "no", and relates to the pain occurring during last one year, weekly prevalence [in last seven days], and any activity restriction due to it [22-24]. 


\section{Oswestry Disability Index}

The ODI was originally developed as a self-assessment tool which gives the subjective impression on a person's state of disability. The ODI has ten questions, each followed by six alternatives. Each question is scored from 0 to 5 , and the sum of the scores is then expressed as a percentage. The ODI has good face validity and content validity, and an acceptable internal consistency [Cronbach's alpha 0.87] [25,26].

\section{GHQ-12}

It is a self-administered test originally developed by Goldberg to assess mental health status of individuals in a general population and in primary health care settings. GHQ-12 is a frequently used screening test and was found to be both valid and reliable for use $[27,28]$.

\section{Work Ability index}

The WAI is an instrument used in clinical occupational health and research to assess work ability during health examinations and workplace surveys. The WAI questionnaire is implemented internationally and has become a methodological benchmark of a comprehensive approach to 'work ability'. It is being used in work place health prevention, in occupational health and reintegration and in science. It may be used for groups as well as for individuals [29].

All teachers were first assessed for inclusion and exclusion criteria. After explaining the need and purpose of the study duly signed consent form was obtained from each participant. The teachers who fulfilled the inclusion criteria were then asked for their demographic details, any present or past medical history, family history, and surgical history. Participating teachers were given clear instruction regarding all the four scales. They were instructed that they have to fill these scales by themselves; no further assistance was given to them. Data was recorded in assessment sheets and data collection form. Analysis of the data was done by using SPSS software (version 14.0).

\section{Results}

The study was conducted to the find out the prevalence of low back pain among higher secondary school teachers of Kanpur. A total of 321 higher secondary school teachers had consented to participate in this present study. The respondents were taken from 13 higher secondary schools in Kanpur city. The mean age of respondents was $42.22 \pm 10.17$, ranging from $26-65$ years old. The mean weight and height were $67.13 \pm 11.36$ and $166.89 \pm 8.85$ respectively. The mean BMI was $24.06 \pm 3.44$ (Table 1). Occupational information regarding number of classes in a week, total working hours and monthly salary is summarized in a (Table 2). The descriptive statistics regarding gender, family type, marital status is documented in (Table 3).

\begin{tabular}{|c|c|c|c|}
\hline Variables & N & Percentage & Mean \pm SD \\
\hline \multicolumn{3}{|c|}{ Age categorization } \\
\hline Age in years & & & $42.22 \pm 10.17$ \\
\hline $26-35$ & 99 & 30.8 & \\
$46-45$ & 96 & 29.9 & \\
$56-65$ & 88 & 27.4 & \\
\hline Height in centimetres & 38 & 11.8 & $166.89 \pm 8.58$ \\
\hline Weight in kilograms & & & $67.13 \pm 11.36$ \\
\hline BMI & & $24.06 \pm 3.44$ \\
\hline \multicolumn{4}{|c|}{ Education } \\
\hline Diploma & 2 & 0.6 & \\
Certificate & 1 & 0.3 & \\
Graduate & 16 & 5 & \\
Post Graduate & 271 & 84.4 & \\
PhD & 31 & 9.7 & \\
\hline N= number of respondents, SD = Standard Deviation \\
\hline
\end{tabular}

Table 1: Socio-demographic characteristics of respondents 


\begin{tabular}{|c|c|c|}
\hline \multicolumn{3}{|c|}{ Occupational information } \\
\hline Number of classes in a week & $36.23 \pm 6.10$ \\
\hline Number of working hours in a week & $41.76 \pm 11.46$ \\
\hline \multicolumn{3}{|c|}{ Salary } \\
\hline 55000 & 25 & 7.8 \\
$10000-10000$ & 25 & 7.8 \\
$15000-15000$ & 50 & 15.6 \\
$20000-25000$ & 14 & 4.4 \\
$25000-30000$ & 2 & 0.6 \\
$\geq 30000$ & 42 & 13.1 \\
\end{tabular}

$\mathrm{n}=$ number of respondents $\mathrm{SD}=$ Standard Deviation

Table 2: Occupational characteristics of the respondents

\begin{tabular}{|c|c|c|}
\hline Characteristic features & \multicolumn{2}{|c|}{ Frequency } \\
\hline \multirow{2}{*}{ Gender } & Mane & 171 \\
\cline { 2 - 3 } & Female & 150 \\
\hline \multirow{2}{*}{ Marital status } & Unmarried & 34 \\
\cline { 2 - 3 } & Married & 287 \\
\hline \multirow{2}{*}{ Family type } & Nuclear family & 188 \\
\cline { 2 - 3 } & Joint family & 133 \\
\hline
\end{tabular}

Table 3: Characteristic information of respondents

\section{Prevalence of low back pain among higher secondary school teachers}

The descriptive analysis of data reveals that $27.7 \%$ and $23.1 \%$ of the higher secondary school teachers were presented with the recent episode (in last 7 days) and yearly prevalence of LBP respectively. Further analysis revealed that $7.2 \%$ of the higher secondary school teachers reported restriction in normal activities of daily living in last one year due to their LBP (Table 4).

\begin{tabular}{|c|c|c|c|}
\hline Nordic musculoskeletal questionnaire & Response & Frequency & Percentage \\
\hline \multirow{2}{*}{ Low back pain last in 7 days } & No & 232 & 72.3 \\
\cline { 2 - 4 } & Yes & 89 & 27.7 \\
\hline \multirow{2}{*}{ Low back pain in last 12 months } & No & 247 & 76.9 \\
\cline { 2 - 4 } & Yes & 74 & 23.1 \\
\hline \multirow{2}{*}{ Restriction in daily living activities in last 12 months } & No & 298 & 92.8 \\
\cline { 2 - 4 } & Yes & 23 & 7.2 \\
\hline
\end{tabular}

Table 4: Descriptive analysis of Nordic musculoskeletal questionnaire showing recent, yearly prevalence of low back pain and restriction in ADL's due to LBP in last 12 months

\section{Disability due to low back pain}

Analysis of data showed that 189 (58.9\%) of higher secondary school teachers fall in the categorization of minimal disability, 115 (35.8\%) had moderate disability, $16(5 \%)$ of the teachers were reported with sever disability and only 1 out of 321 teachers was completely crippled due to low back pain (Table 5).

\begin{tabular}{|c|c|c|}
\hline Oswestry Disability Index category & Frequency & Percentage \\
\hline Minimal disability & 189 & 58.9 \\
\hline Moderate disability & 115 & 35.8 \\
\hline Severe disability & 16 & 5 \\
\hline Crippled & 1 & 0.3 \\
\hline Bed bound & 0 & 0 \\
\hline
\end{tabular}

Table 5: Descriptive analysis of Oswestry disability index

\section{Impact of disability due to low back pain on work ability}

Pearson correlation analysis showed that disability due to low back pain has a significant correlation with work ability. $\mathrm{R}$ value $=$ $-0.505^{\star \star}$ (Figure 1). 


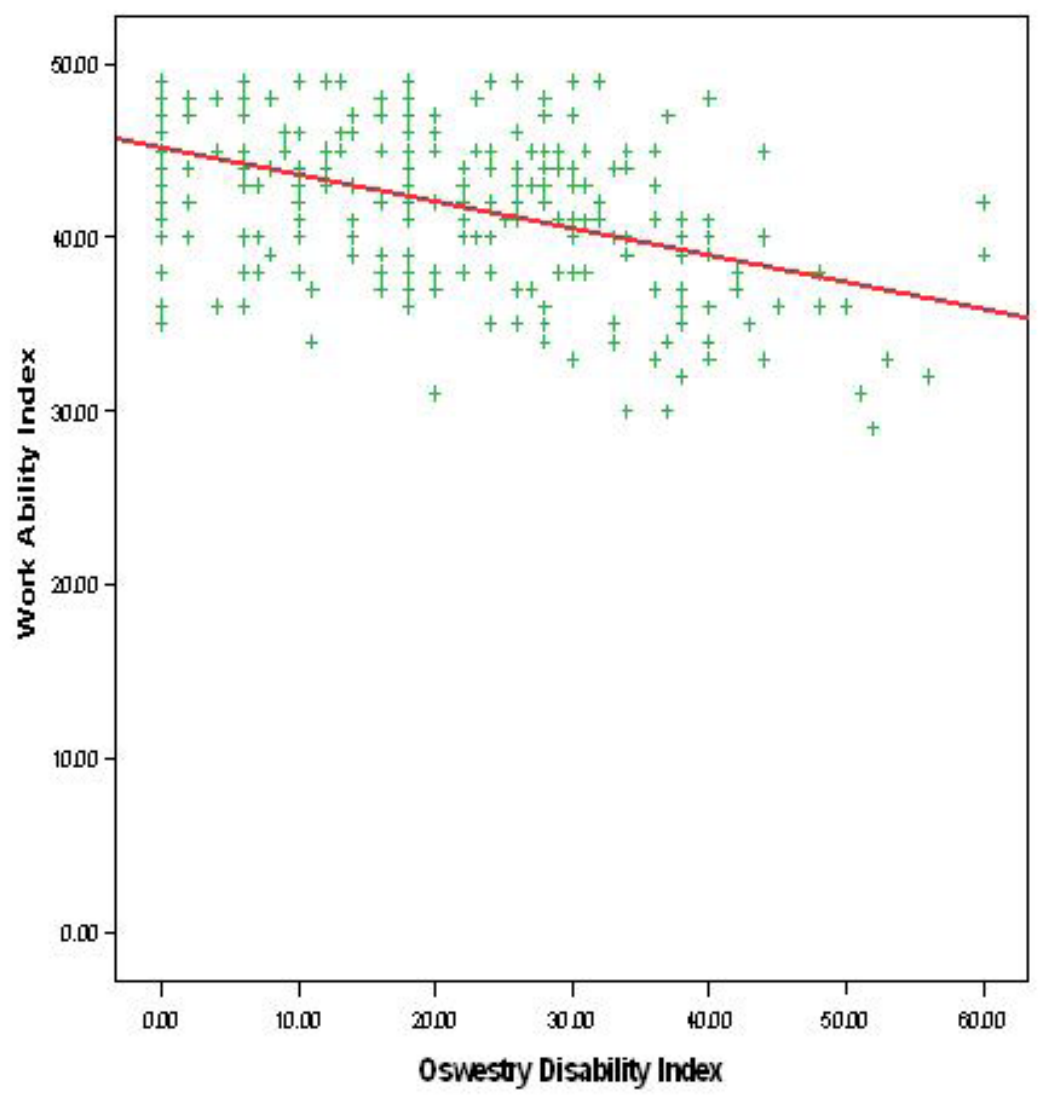

Figure 1: Correlation between Oswestry disability index and work ability index

\section{Impact of disability due to low back pain on general psychological wellbeing}

Statistical analysis showed significant correlation between disability due to low back pain and general psychological wellbeing. $\mathrm{R}$ value $=0.469^{* *}($ Figure 2$)$.

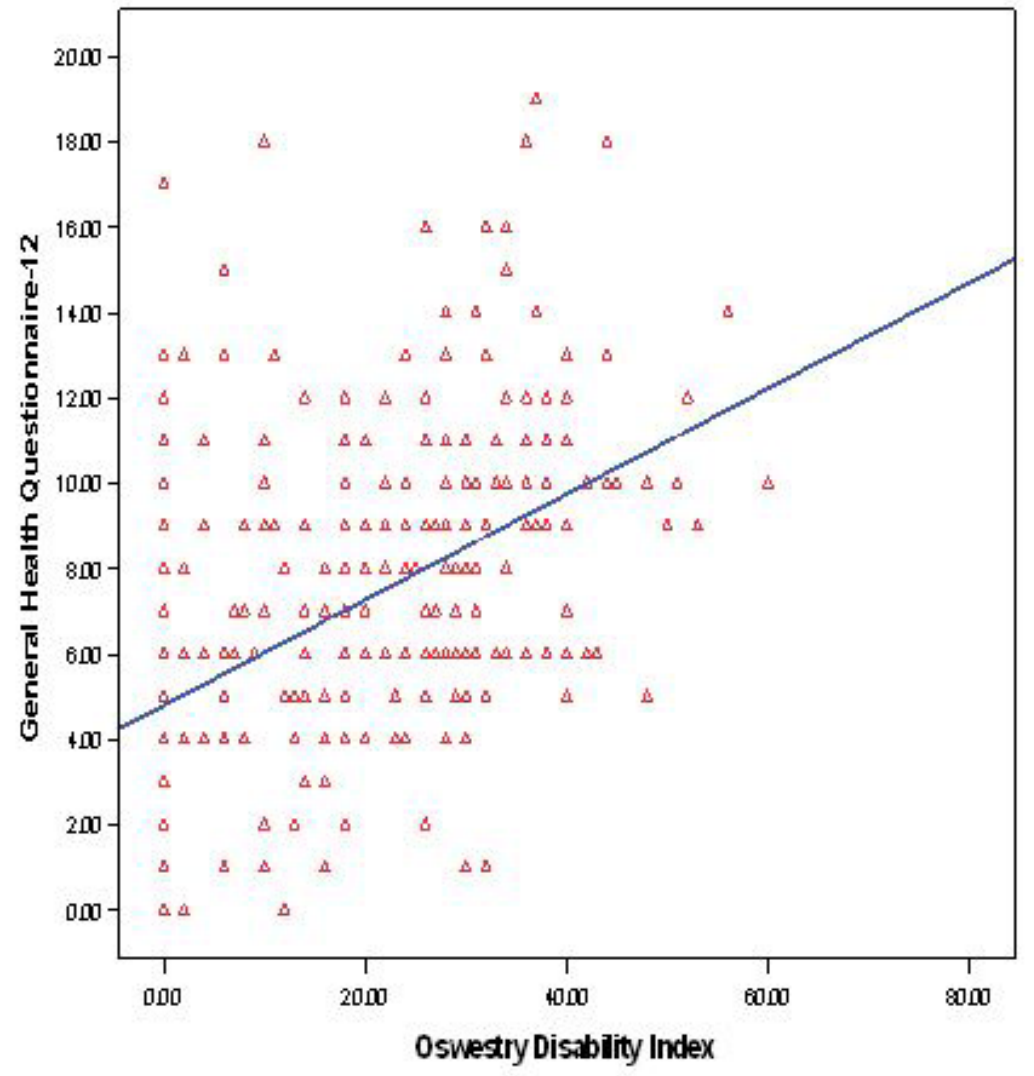

Figure 2: Correlation between Oswestry disability index and general health questionnaire 


\section{Discussion}

This study was an attempt to investigate the prevalence of LBP among higher secondary school teachers. The average age of teachers was $42.22 \pm 10.17$ with 41 mean working hours in a week. $34 \%$ of teachers were post graduate and half of the responding teachers had monthly salary of more than 30,000 Indian rupees.

\section{Prevalence}

Findings of our study revealed that $28 \%$ teachers have point prevalence (acute) of LBP and 23\% teachers had yearly prevalence of self-reported LBP. Similarly, in a study done by Tsuboi et al. 2002 similar prevalence of LBP (20.4\% in men and 23.2\% in women) was documented among the school personnel in Nagoya, Japan [30]. Durmus et al 2012 identified LBP as the most common workrelated ailment among teachers [31]. According to the third European survey on working conditions in 2000 (ESWC) conducted across all sectors, education was seen to have the lowest exposure to repetitive hand or arm movements (20\%). Just 15\% of workers in education are exposed to working in painful positions. The data shows that the education sector has the lowest percentage of workers exposed to the risk factors associated with LBP symptoms [18].

However, there is abundant of literate available which suggests that teachers are at high risk of LBP, which is in contrast to the literature saying prevalence of LBP was low. In our study it is also revealed that $35.8 \%$ of the higher secondary school teachers had moderate disability due to their LBP. This means that more than one third of the higher secondary school teachers had difficulty in performing their work due to their self-reported LBP. This is an alarming fact as teachers are primarily responsible for building our future generation. Job nature of school teachers includes frequent reading, marking of assignment, writing on black board [17]. Long teaching hours, overhead writing, prolonged sitting with neck flexion, twisting, such as turning from the board to the class and back again and working on computers are involved with their routine work. Awkward postures like overhead writing on black boards, neck flexion during marking or reading, and poking chin while working on computers put muscles at a sustained strained position. Working in these positions for long periods day after day is one of the most problematic job factors [32]. There is a possible relationship between the local mechanical pressure and the onset of musculoskeletal problem repetitive work manifested as myalgia which could probably be due to impedance of circulation [33]. Prolonged standing is also probably a cause for back pain and pain in the feet [34].Thus available findings go to prove that job related mechanical factors do contribute in developing LBP among teachers.

Secondary findings of our study suggest that LBP has a significant impact on working ability and the psychological wellbeing of the teachers. It shows that presence of LBP has a negative impact on the work ability of a teacher and with the presence of LBP the psychological wellbeing also gets affects. Teachers play a versatile role in not just educating students but also acting as a role model through their general behaviour, pose and posture. Hence their actions and behaviour would directly influence the students [35].The teaching profession is known for having many job demands [36]. It is believed that musculoskeletal disorder develops over time and is caused either by work itself or by the employees' working environment [36]. The monotonous nature of work is most likely associated with LBP among school teachers. This may occur because teachers often work in stressful conditions with large classes, there is generally a lack of educational resources, limited reward for their work, irate and unpredictable student behaviour and uninspiring relationship with administration and colleagues. Yilmaz et al. (2012) has reported that psychological factors at work contribute significantly towards LBP [37]. Tuomi K et al. (1991) in their study also reported that musculoskeletal disease affects the work ability. They concluded that as soon as the first signs of decreasing work ability are noticed early preventive measures should be taken for better effects [12].

Yi-Shiung Hoeng et al. (2007) also concluded that musculoskeletal disorders have negative impact on work ability and job performance. He also concluded that there is a significant interaction between pain intensity and the psychological factors [38]. In the present study we too found that musculoskeletal discomfort has a significant impact on general psychological wellbeing. Hence programs to prevent musculoskeletal disorder should often be performed.

In our study we found that LBP had a significant correlation with age. Musculoskeletal low back pain is likely to become more prevalent as the age increases. In a critical review Erick et al. also reported that there is a strong correlation between musculoskeletal disorders and the individual's physical and psychological factors. Individual factors such as gender, age, length of employment and work hours are associated with musculoskeletal disorder. Juhani et al. (1997) in his study suggested that measures to promote work ability should be initiated before the age of 51 years, especially for workers in physically demanding jobs. Future studies are needed to examine the effect of health education and ergonomic measure on prevalence of LBP [39]. Also, there is a need to identify various work related stress causing LBP among higher secondary school teachers.

\section{Limitations of the study}

Data collection was not done using random sampling method. Also, it is possible that the respondents might have given indistinguishable answers or exaggerated their LBP. 


\section{Limitations of the study}

Data collection was not done using random sampling method. Also, it is possible that the respondents might have given indistinguishable answers or exaggerated their LBP.

\section{Practical Implication}

Finding of the present study provide important information regarding the presence of LBP and resulting disability among higher secondary school teachers of Kanpur city. Findings of the present study must be viewed as an alarming sign to recognize LBP and related disability among teachers. School management and healthcare policy makers must work for the optimization of work system, to minimize the risk of injury and to maximize productivity. Healthcare system should emphasise on the primary as well as secondary prevention of LBP among higher secondary school teachers. The results also provide backdrop for future researches both nationally or internationally.

\section{Conclusion}

Finding of the present study suggests that though both point and yearly prevalence of LBP among higher secondary school teachers is low but the disability due to it is affecting more than one third of the higher secondary school teachers. Second inference is that LBP have a negative impact on work ability and general psychological wellbeing of teachers.

\section{References}

1. Shipp EM, Cooper SP, Del Junco DJ, Delclos GL, Burau KD, et al. (2007) Severe back pain among farm worker high school students from star county, Texas: baseline results. Ann Epidemiol 17: 132-141.

2. Tucer B, Yalcin BM, Ozturk A, Mazicioglu MM, Yilmaz Y, et al. (2009) Risk factors for low back pain and Its Relation with pain related disability and depression in a Turkish sample. Turk Neurosurg 19: 327-32.

3. Middelkoop MV, Rubinstein SM., Verhagen AP, Ostelo RW, Koes BW, et al. (2010) Exercise therapy for chronic nonspecific low-back pain. Best Pract Res Clin Rheumatol 24: 193-204.

4. Odole AC, Adegoke BOA, Akinpelu AO, Okafor AC (2010) Low Back Pain At Work: Knowledge and Attitude of Sectional Heads At the University College Hospital, Ibadan. AJPARS 3: 28-35.

5. Shah S, Dave B (2012) Prevalence of Low Back Pain and Its Associated Risk Factors among Doctors in Surat. Int J Health Sci Res 2: $91-102$.

6. Azize K, Kav S, Abbasoglu A, Dogan N (2008) Low back pain: prevalence and associated risk factors among hospital staff. J Adv Nurs 65: 516-24.

7. Nagasu M, Sakai K, Ito A, Tomita S, Temmyo Y, et al. (2007) Prevalence and risk factors for low back pain among professional cooks working in school lunch services. BMC Public Health 17: 1-10.

8. Bridget B, Dienye P, Ndukwu G (2012) Prevalence of Low Back Pain Among Peasant Farmers In A Rural Community In South South Nigeria. Rural Remote Health 12: 1920.

9. Beyen TK, Mengestu MY, Zele YT (2013) Low Back Pain and Associated Factors among Teachers in Gondar Town, North Gondar, Amhara Region, Ethiopia. Occup Med Health Aff 1: 127.

10. Ogunbode AM, Adebusoye LA, Alonge TO (2013) Prevalence of Low Back Pain And Associated Risk Factors Amongst Adult Patients Presenting To A Nigerian Family Practice Clinic, A Hospital-Based Study. Afr J Prim Health Care Fam Med 5: 441.

11. Wong TS, Teo N, Kyaw MO (2010) Prevalence and Risk Factors Associated with Low Back Pain Among Health Care Providers in a District Hospital. Malaysian Orthopaedic Journal 4.

12. Tuomi K, Ilmarinen J, Eskelinen L, Järvinen E, Toikkanen J, et al. (2011) Prevalence and incidence rates of diseases and work ability in different work categories of municipal occupations. Scand J Work Environ Health 37: 455-63.

13. Hasselhorn HM (2008) Work Ability - Concept and Assessment. Enterprise for Health Management Conference in London 1-10

14. Kloimüller, Karazman R, Geissler H, Karazman-Morawetz I, Haupt H (2000) The relation of age, work ability index and stress - inducing factors among bus drivers. Int J Ind Ergonomics 25: 497-502.

15. Kaur S (2011) Comparative Study of Occupational Stress among Teachers of Private and Govt. Schools in Relation to their Age, Gender and Teaching Experience. Int J Educ Plann Admin 1: 151-60.

16. Aftab M (2012) Demographic differences and occupational stress of secondary school teachers. Eu Sci J 8: 159-75.

17. Chaiklieng S, Suggaravetsiri P (2012) Risk factors for repetitive strain injuries among school teachers in Thailand. Work 41: $1051-9815$.

18. Başkurt F, Kara B, Başkurt Z (2011) The Assessment of Pain and Hand Functions of Patients with Anterior cervical disc surgery. J Neuro Sci 28 : 337-46.

19. Samad NIA, Abdullah H, Moin S (2010) Prevalence of Low Back Pain and its Risk Factors among School Teachers. Am J Appl Sci 7: 634-9

20. Santana A, De Marchi D, Junior LC, Girondoli YM, Chiappeta A (2012) Burnout syndrome, working conditions, and health: a reality among public high school teachers in Brazil. Work 41: 3709-17.

21. Lederman E (2011) The fall of the postural-structural-biomechanical model in manual and physical therapies: Exemplified by lower back pain. J Bodyw Mov Ther 19: 131-8.

22. Crawford JO (2007) The Nordic Musculoskeletal Questionnaire. Occup Med 57: 300-1.

23. Dickinson CE, Campion K, Foster AF, Newman SJ, O’Rourke AM, et al. (1992) Questionnaire development: An examination of the Nordic Musculoskeletal Questionnaire. Appl Ergon 13: 197-201.

24. Kuorinka I, Jonsson B, Kilbom A, Vinterberg H, Biering-Sørensen F, et al. (1987) Standardized Nordic Questionnaire for the analysis of musculoskeletal symptoms. Appl Ergon 18: 233-7.

25. Niskanen RO (2002) The Oswestry low back pain disability questionnaire a two-year follow-up of spine surgery patients. Scand J Surg 91 : $208-11$. 
26. Fairbank JC, Pynsent PB (2000) The Oswestry Disability Index. Spine (Phila Pa1976) 25: 2940-52.

27. Sarp üner, Hilal özcebe, Gökhan telatar T, Sabahat tezcan (2008) Assessment of Mental Health of University Students with GHQ-12. Turk J Med Sci 38: 437-46.

28. Fairbank JCT, Pynsent PB (2000) The Oswestry disabilitry index. Spine 25: 2940-53.

29. The Work Ability Index (WAI) (2007) Oxford Academic. Occupational Medicine 57: 160.

30. Tsuboi H, Takeuchi K, Watanabe M, Hori R, Kobayashi F (2002) Psychosocial Factors Related to Low Back Pain among School Personnel in Nagoya, Japan. Ind Health 40: 266-71.

31. Durmus D, Ilhanli I (2012) Are there work-related musculoskeletal problems among teachers in Samsun, Turkey? J Back Musculoskelet Rehabil 25: 5-12.

32. John Son WMS, Bertha A, John Son PS (2011) Prevalence of Upper Extremity Musculoskeletal Disorders among workers in an industrial town in Tamil Nadu. Journal of Clinical and Diagnostic Research 5: 187-90.

33. Güllü M, Meneve A, Arslan C (2012) Comparison of levels of occupational diseases between physical education teachers and teachers in other branches. World J Med Sci 7: 178-84.

34. Hakanen JJ, Aanold BB, Wilmer BS (2006) Burnout and work engagement among teachers. Journal of School Psychology 43: $495-513$.

35. Erick P, Smith D (2013) Risk factors of musculoskeletal disorders among teachers: A critical review. OA Musculoskeletal Medicine 1: 29.

36. Morrison SM (2005) Occupational stress in school teachers: A descriptive-comparative study. The University of New Brunswick.

37. Yilmaz E, Dedel O (2012) Effect of physical and psychosocial factors on occupational low back pain. Health science journal 6: $598-609$.

38. Hsin-Yi Kathy Cheng, Man-Ting Wong, Yu-Chung Yu, Yan-Ying Ju (2008) Work-related Musculoskeletal Disorders of the Workers in a Child Care Institution. Tw J Phys Med Rehabil 36: 15-21.

39. Ilmarinen J, Tuomi K, DSocSc (1997) Changes in the work ability of active employees over an 11 -year period. Scand J Work Environ Health 23 : $49-57$.

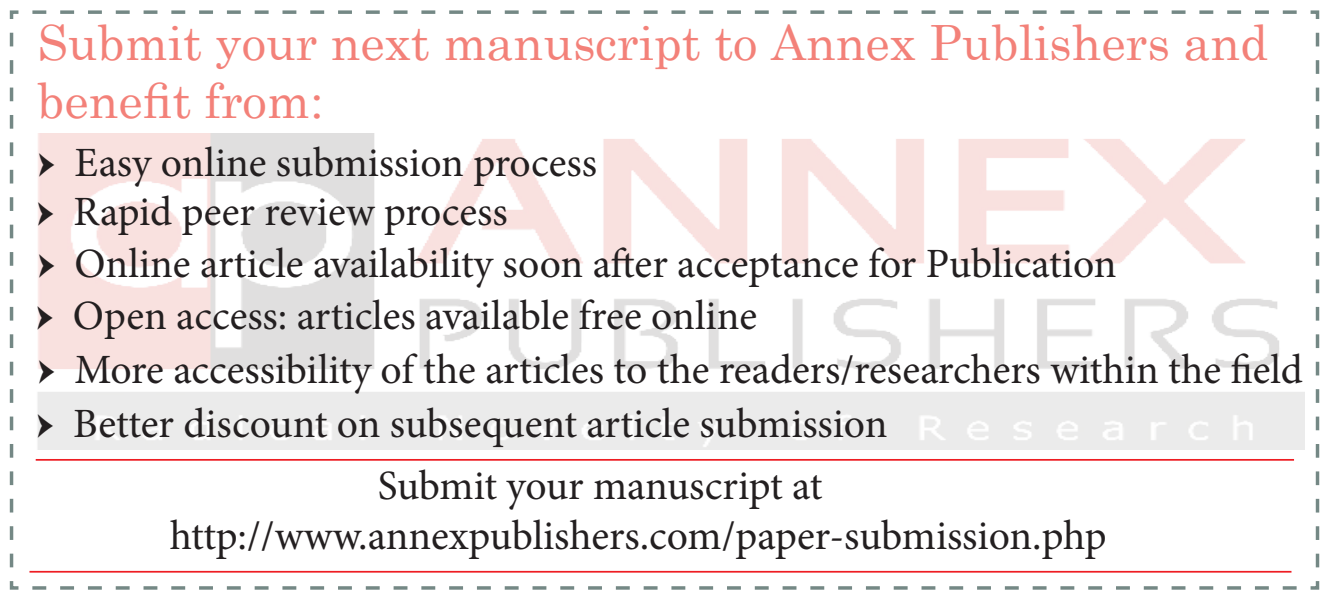

